\title{
Anatomical Study of the Variations of Sinuatrial and Atrioventricular Nodal Arteries in Human Heart
}

\author{
Verma $\mathbf{R}^{1}$, Guha BK${ }^{2}$, Shrivastava $\mathrm{SK}^{3}$ \\ ${ }^{1}$ Dr Ranjana Verma, Post Graduate Student in Anatomy, ${ }^{2}$ Dr B K Guha, Associate Professor of Anatomy, ${ }^{3}$ Dr S K \\ Shrivastava, Professor \& Head. All are affiliated with Department of Anatomy, N S C B Medical College, Jabalpur, MP, \\ India
}

Address for correspondence: Dr Ranjana Verma, Email: ranjana4anvi@gmail.com

\begin{abstract}
Introduction: The conducting system of the heart is supplied mainly by Sinuatrial nodal artery and Atrioventricular nodal artery. Generally, in 60\% subjects, Sinuatrial nodal artery arise from Right Coronary Artery and in remaining 40\% it arise from Left circumflex branch of Left Coronary Artery. Similarly, the atrioventricular nodal artery arises from Right Coronary Artery in $80 \%$ and from Left Coronary Artery in $20 \%$ subjects. The aim of the present study is to observe the variation of Sinuatrial \& Atrioventricularnodal arteries in human hearts for gathering adequate information study which may be helpful for cardiovascular surgeries. Material and Method: Present study included 50 human hearts. Heart specimens obtained from department of Anatomy of Netaji Subhash Chandra Bose medical College, Jabalpur, India. The course of Sinuatrial nodal and Atrioventricular nodal arteries were traced by micro dissection under water method. Results: In the present study Sinuatrial nodal artery arose from RCA in 52\% cases, from LCA in $24 \%$ cases and in $24 \%$ cases it arose from both RCA \& LCA. Likewise, Atrioventricular nodal artery arose from RCA in $88 \%$ cases and in $12 \%$ cases it arose from LCA. Conclusion: Considering the necessity of Open heart surgeries it becomes necessary to have a deep knowledge of origin and variation of Sinuatrial nodal and Atrioventricular nodal arteries. Knowledge of variation in the blood supply of conducting system may help cardiac surgeons in taking due cautions during various cardiac surgeries, atrial surgical interventions and surgery related to certain valvular disorder and congenital malformation.
\end{abstract}

Key words: Sinuatrial Nodal Artery, Atrioventricular Nodal Artery, Sinuatrial Node, Atrioventricular Node, Coronary Artery.

\section{Introduction}

The Sinuatrial node, Atrioventricular node and networks of the specialized myocardial cells constitute the cardiac conduction system. The SA node is elliptical mass of histologically distinct myocardial cells. It is $10-20 \mathrm{~mm}$ long subepicardially situated in the wall of the right atrium, just below the superior vena cava, at the top of the sulcus terminalis. It has no macroscopic or palpable features that indicate its location [1].

The main pacemaker rhythm of the heart is generated at SA node \& transmitted specifically from atria to ventricles through AV node and bundle of his, within the ventricles, to all their musculature. AV node lies subendocardially in the triangle of Koch between the anteromedial margin of the coronary sinus ostium, the

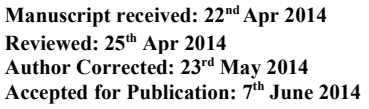

International Journal of Medical Research and Review base of the septal cusp of the tricuspid valve and the tendon of Todaro, which lies between the central fibrous body or the right fibrous trigone (trigonumfibrosumdextrum) and the medial border of the Eustachian valve (valvula venae cavaeinferioris). The tendon of Todaro is a subendocardial connective tissue band that connects the commissure of the Eustachian and Thebesian valves [2].

The artery of the SA node is an atrial branch, thus, 'nodal' artery usually passes back in the groove between the right auricular appendage and aorta. Generally in 60\% subjects the SA nodal artery arises from right coronary artery $\&$ in $40 \%$ subjects it comes from the circumflex branch of the left coronary [1]. When this is the case, this branch travels upward along the left atrium, behind the aorta to the anterior interatrial sulcus, and continues rightward to partially encircle the lower portion of the superior vena Available online at: www.ijmrr.in 209 | P a g e 
cava. The SA nodal artery usually gives branches around the base of the superior vena cava, typically as an arterial loop from which small branches supply the right atrium. The dual supply of SA node from coronary system becomes a protective anatomical substrate for any atheromatosis processes involving these vessels that can alter sinus rhythm.

The largest posterior septal artery, usually arises from the inverted loop of right coronary artery at crux, supplies AV node in $80 \%$ heart \& from the circumflex artery in $20 \%$ subjects [3].

As per Halsted, a pioneer American surgeon, the best way to avoid injury to a blood vessel is to know about its course and branching pattern. Hence, Anatomists bear a great responsibility of research, understanding and spreading the knowledge of arterial variations.

The aim of the present study is to observe the variation of Sinuatrial \& Atrioventricularnodal arteries in human hearts for gathering adequate information study which may be helpful for cardiovascular surgeries.

\section{Material \& Methods}

The heart specimens for this study were obtained from cadavers in the department of Anatomy of NSCB medical college, Jabalpur, India. The sample size for this study was 50 heart specimens.

The ribs and sternum were cut, thus opening the thoracic cavity. All the great vessels were ligated by thread at two places and cut in between. The parietal pericardium was incised and the heart was taken out of the pericardial cavity.

The specimens were numbered from 1 to 50 and preserved in $10 \%$ farmaldehyde solution. The dissection was done under water. The visceral pericardium was removed and by micro dissection the RCA and LCA was exposed. Then SA nodal \& AV nodal arteries were traced from their origin $\&$ their course, the branching pattern $\&$ variations were noted. Red acrylic colour was used to paint the SA \& AV nodal arteries to give contrast in photographs. Photographs of specimen were taken by Sony digital camera of 20.2 megapixels and labelled.

\section{Results}

Table-I: Blood Supply of SA Node

\begin{tabular}{|c|c|c|}
\hline \multirow{2}{*}{ Source } & \multicolumn{2}{|c|}{ Number and percentage of specimens (N=50) } \\
\cline { 2 - 3 } & No. & 52 \\
\hline RCA & 26 & 24 \\
\hline LCA & 12 & 24 \\
\hline Both & 12 & $\%$ \\
\hline
\end{tabular}

In the present study, Right coronary artery supplied to SA node in 26 specimens i.e. 52\% (See fig.I). Similarly, Left coronary artery supplied to SA node in 12 specimens i.e.24\% (See fig.II). However, SA node was supplied by both the arteries in 12 specimens (See fig. III).

Table-II: Origin of AV Nodal Artery

\begin{tabular}{|c|c|c|}
\hline \multirow{2}{*}{ Source } & \multicolumn{2}{|c|}{ Number and percentage of specimens $(\mathrm{N}=50)$} \\
\cline { 2 - 3 } & No. & $\%$ \\
\hline RCA & 44 & 88 \\
\hline LCA & 6 & 12 \\
\hline
\end{tabular}

In the present study, in 44 specimens (88\%) AV nodal artery was branch of Right coronary artery (See fig. IV). However, in six specimens, i.e. $12 \%$, AV nodal artery was branch of Left coronary artery (See fig. V).

\section{Discussion}

Coronary artery variation is being examined by Clinicians and Anatomists from a long time. Since 1960, when the selective coronary angiography began, the total numbers of investigations in this field have increased. However, there is still no consensus on the normality or abnormality of coronary artery rather variation in the branching pattern of coronary artery is the peculiarity of coronary artery. 
Research Article

They were Keith \& Flack who, in 1907, described SA node for first time [4]. It is a pacemaker and considered very important structure in the heart. Due to its functional importance, the blood supply of this important structure has great value. The nature of the blood supply to the SA node influences the clinical expression of sinuatrial nodal ischemia and related diseases.

Vascular descriptions of nodal arteries have been reported in several published articles in literature and we agree that in majority of hearts nodal arteries are given by right coronary artery (52\% in our study),(See table-III) but in present study we find high incidence (24\%) of dual blood supply of SA node (See photo.-I). The dual supply of SA

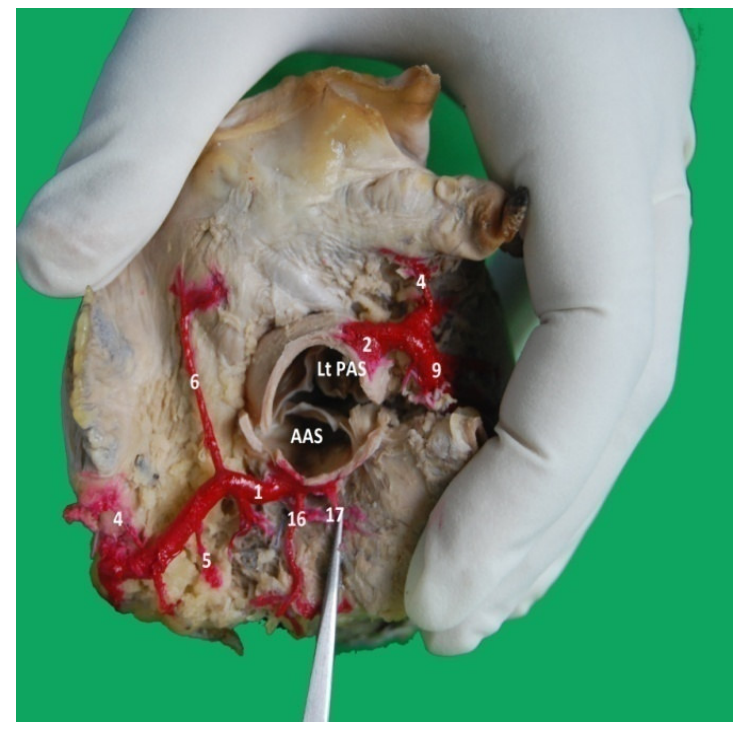

Figure-I: Origin of SA nodal artery (6) from RCA (1)

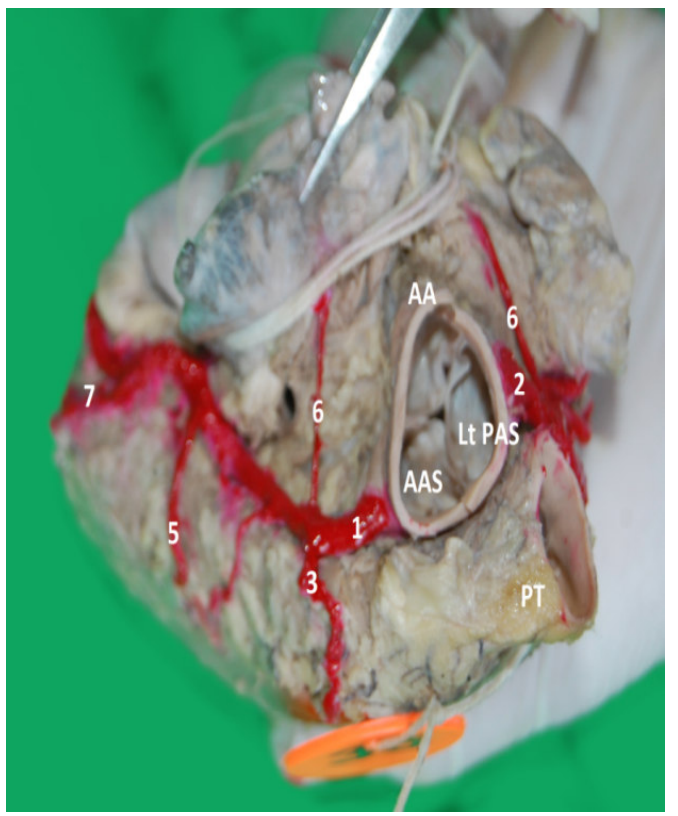

Figure-III: Origin of sinuatrial nodal artery (6) from RCA (1) \& LCA (2) both (Superior View)

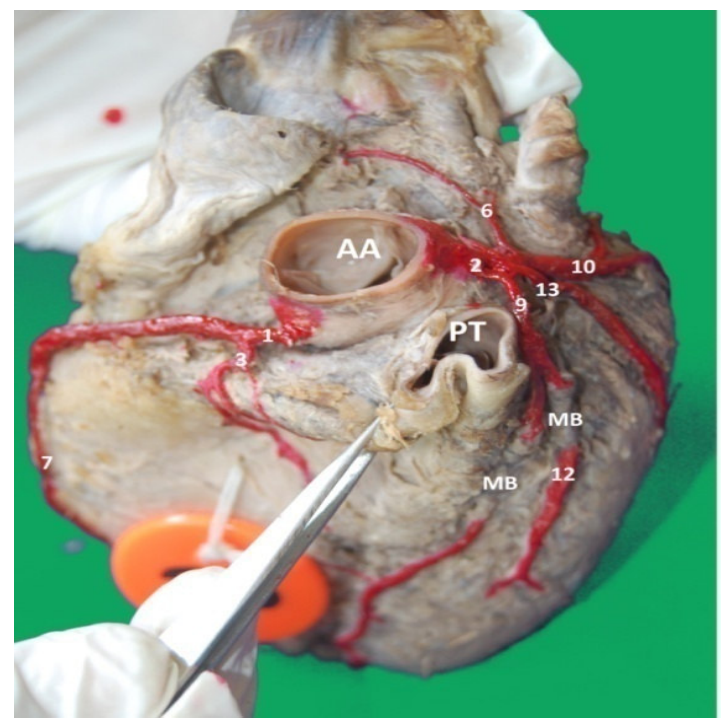

Figure-II: Origin of sinuatrial nodal artery (6) from Lt Circumflex Artery (10) (Anterosuperior View)

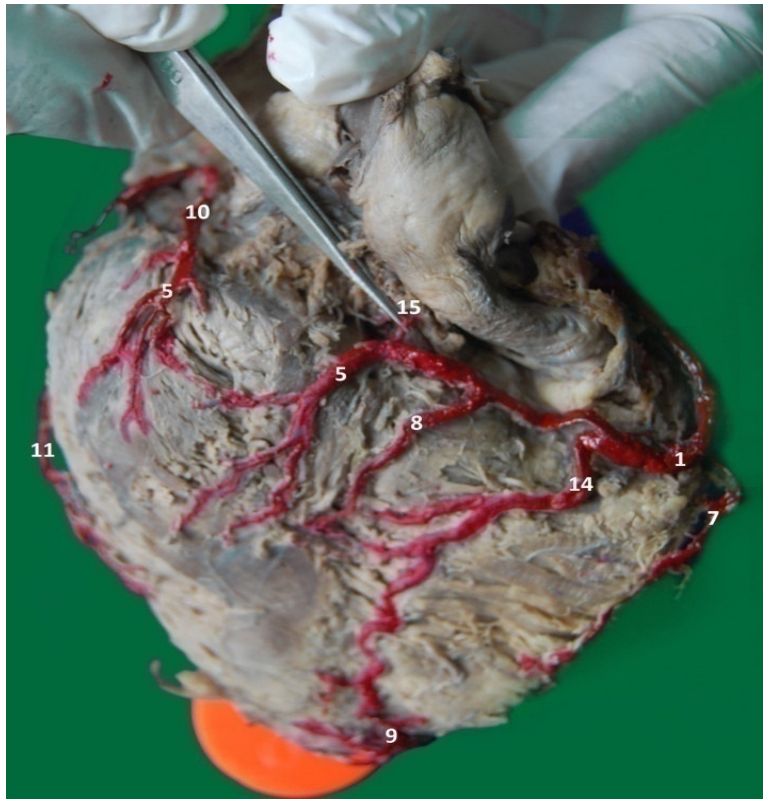

Figure-IV: Origin of AV nodal artery (15) from RCA (1). (Posterior view)

node from both RCA \& LCA becomes a protective anatomical substrate for any atheromatosis processes involving these vessels that can alter sinus rhythm. Futami [5] also reported the double origin of SA nodal artery in $23 \%$ cases of Japanese population. Thus percentages of SA node supplied by both coronary arteries as noted by various scholars ranges between 3.3 to $23 \%$. 


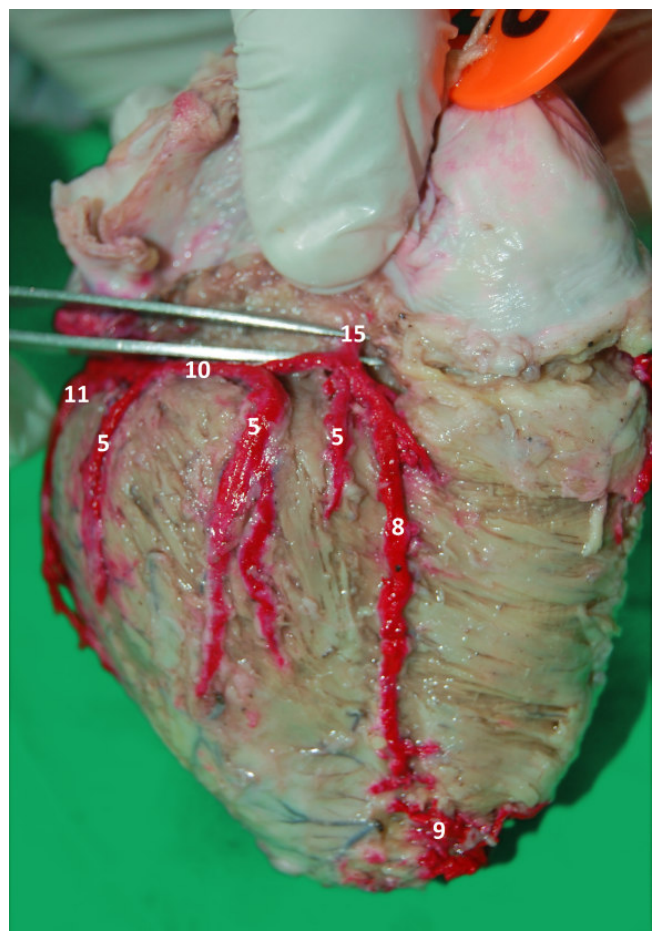

\section{Keys to Photographs}

1-Right Coronary Artery, 2-Left Coronary Artery, 3-Right Conus Artery, 4-Atrial branch, 5-Ventricular branch, 6-Sino-atrial Nodal Artery, 7-Right Marginal Artery, 8-Posterior Interventricular Artery, 9-Left Anterior descending Artery, 10-Left Circumflex Artery, 11 -Left Marginal Artery, 12 -Left Diagonal Artery, 13Median artery, 14-Posterior Right Diagonal Artery, 15-Atrio ventricular Nodal Artery, 16-Third Coronary Artery, 17-Fourth Coronary Artery, RA-Right Atrium, LA-Left Atrium, AA-Ascending Aorta, PT-Pulmonary trunk, AAS-Anterior Aortic Sinus, PAS-Posterior Aortic Sinus

Table-III: Comparison of variations in blood supply of SA and AV nodes as reported in literature

\begin{tabular}{|c|c|c|c|c|c|c|c|}
\hline \multirow{2}{*}{ S. No. } & Study done by & \multicolumn{3}{|c|}{ SinuatrialNode } & \multicolumn{3}{c|}{ Atrioventricular Node } \\
\cline { 2 - 8 } & RCA & $\begin{array}{c}\text { LCA } \\
(\%)\end{array}$ & $\begin{array}{c}\text { Both } \\
(\%)\end{array}$ & $\begin{array}{c}\text { RCA } \\
(\%)\end{array}$ & $\begin{array}{c}\text { LCA } \\
(\%)\end{array}$ & $\begin{array}{c}\text { Both } \\
(\%)\end{array}$ \\
\hline 1. & Baroldi and Scomazzoni $(1956)^{6}$ & 51 & 41 & 8 & - & - & - \\
\hline 2. & James $(1961)^{7}$ & 54 & 42 & 4 & - & - & - \\
\hline 3. & Futami C $(2003)^{5}$ & 73 & 3 & 23 & 80 & 10 & 10 \\
\hline 4. & Kalpana R $(2003)^{8}$ & 56 & 35 & 8 & 82 & 18 & - \\
\hline 5. & K.V. Venkateshu $(2006)^{9}$ & 96.3 & - & 3.3 & 86.5 & 13.3 & - \\
\hline 6. & Pejkovic B $(2008)^{2}$ & 63 & 37 & - & 90 & 10 & - \\
\hline 7. & Anjali S Sabnis $(2012)^{10}$ & 90 & 10 & - & 70 & 29 & 0.9 \\
\hline 8. & Present study $(2014)$ & 52 & 24 & 24 & 88 & 12 & - \\
\hline
\end{tabular}

The largest arterial branch, arising from the first or second centimeter of the main vessel is usually the SA nodal artery which forms a vascular ring in the right atrium and auricle below the superior venacaval opening. This supplies the SA node in almost $60 \%$ of hearts and may arise directly from the anterior aortic sinus adjacent to the right coronary itself.Among 110 autopsy cases Anjali s Sabniset al [10] found that, in one heart right marginal artery was arising from right coronary artery much proximally. Instead of right coronary artery, SA nodal artery took origin from right marginal artery. Schlesinger et al [11] and James [7] have described the origin of SA

Available online at: $\underline{\text { www.ijmrr.in }} 212$ | P a g e 
nodal artery directly from the aortic sinuses in some instances. The anatomic features of the SA nodal artery are very important in cardiac surgery. The base of the superior vena cava at the superior atriocaval junction, the anterior and lateral walls of the right or left atria, particularly opposite the proximal segments of the RCA, the roof of the atria, the interatrial septum are some regions at which major risks of damaging or dividing the SAN exists [12].

In the current study the blood supply to the SA node was found from the left coronary artery in $24 \%$ cases; this compares with previously reported incidences which ranges between 3 to $41 \%$ (See table-III). It has been found to be a branch of theLt.Circumflex branch either just distal to division of main trunk of LCA or from proximal part of lt. circumflex artery, but, sometimes arises directly from the left coronary artery [13]. It then usually ascends the left atrial wall behind the aorta, reaches the anterior interatrial groove and then takes the same course as when originating from the right coronary artery.B Pejkovicet al. [2] noted that in $2 \%$ cases the SA node artery has been found to arise from the distal portion of the circumflex branch of the left coronary artery as the left lateral (intermediate) atrial branch or as the posterior atrial branch parallel to the circumflex branch.

AV node was first described by Tarawa ${ }^{4}$ in 1906 . The main function of $\mathrm{AV}$ node is modulation of atrial impulse transmission to the ventricles, there by coordinating atrial and ventricular contractions. It delays the impulse received from S.A node and protect ventricles from atrial arrhythmia. The largest posterior septal artery from right coronary artery which is given at crux enters the interatrial septum and supplies AV node. This artery is important vessel in the pathogenesis of heart block.

Any variation in point of origin, course may provide information prior to catheter based interventional cardiac procedure $^{14}$. The origin of AV nodal artery is related to coronary artery dominance. In right dominance it usually arises from RCA and in left dominance it arises from lt. circumflex branch of LCA. We found that AV nodal artery is arising from RCA in $88 \%$ specimens (See photo.III); this compares with previously reported incidences ranges between 70 to $90 \%$. It arises from LCA in $12 \%$ specimen (see photo. - IV) and in 10 to $29 \%$ specimens by other authors (see table - III). Futami [5] and Anjali S Sabnis [10] also noted origin of AV nodal artery from both LCA and RCA but we did not find such type of variation. The close proximity of the AV node artery to the mitral valvular ring explains the rhythm disorders that can occur during mitral valve surgery. In such cases the risk of injuring the AV node artery is increased.
Awareness of anatomical variants of SA nodal \& AV nodal arteries may guide theCardiac surgeons during cardiac procedures and reduces the risk of damaging them.

\section{Conclusion}

Now-a-days open hearts surgeries are being performed widely. It needs precaution to maintain existing anastomosis for normal functions of heart. Considering the necessity of these surgeries it becomes necessary to have a deep knowledge of origin and variation of Sinuatrial nodal and Atrioventricular nodal arteries.

Knowledge of variation in the blood supply of conductive system may help cardiac surgeons in taking due cautions during various cardiac surgeries, atrial surgical interventions and surgery related to certain valvular disorder and congenital malformation.

It may also be beneficial for methods of cardiological examination and treatment to have detailed knowledge of the arterial supply of the SA \& AV nodes. Proper precautions may be taken to preserve the main arterial supply to the sinus node during surgery through this knowledge.

\section{Funding: Nil}

\section{Conflict of interest: Nil}

\section{Permission from IRB: Yes}

\section{Reference}

1. Chummy S Sinnatamby. Last's anatomy Regional and applied 11Edition. Elsevier Churchill Livingstone. 2006; 210.

2. B Pejkovi'C1, I Krajnc2, F Anderhuber3 And D Košuti'C. Anatomical Aspects of the Arterial Blood Supply to the Sinuatrial and Atrioventricular Nodes of the Human Heart.J Int Med Res. 2008; 36: 691 - 698.

3. Standring S. The anatomical basis of clinical practice. 39th ed. Philadelphia: Elsevier Churchill Livingstone. 2005:1014-18.

4. Hurst, Willis J. The Heart. 7th edition Vol. I, Part I, Mc-Graw Hill, New york, Information sevices company. 1990; p-14-35.

5. Futami C, Tanuma K, Tanuma Y, Saito T. The arterial blood supply of the conducting system in normal human hearts. 
6. Baroldi G, Mantero O, Scomazzoni G. The collaterals of the coronary arteries in normal and pathologic heart. Circulation Research. 1956; 4:223-9.

7. James TN. Anatomy of the coronary arteries. Hoeber, New York. Circulation. 1965;32:1020-33.

8. Kalpana R. A study of principal branches of coronary arteries in human. J anat soci India.2003Dec;52(2):137-40

9. Venkateshu KV. A study of arterial supply of SA node and AV node. Anat Karnataka. 2006 July; 2(2):21-24.

10. Anjali S Sabnis, Nazmeen N Silotry. Anatomical variations of nodal arteries in human hearts. Journal of
Evolution of Medical and Dental Sciences. 2012 Oct; 1(4):482.

11. Schlesinger MJ, Zoll PM, Wessler S. The conus artery: a third coronary artery. Am HeartJ.1949;38:823-36

12. Sow ML, Ndoye JM, Lô EA. The artery of the sinuatrial node. SurgRadiol Anat. 1996;18:103-109.

13. James TN, Burch GE. The atrial coronary arteries in man. Circulation. 1958; 17: 90 - 98.

14. Duzgun Y. Anatomy \& variations of arterial supply to sinuatrial node: Imaging with dual source cardiac multidetector CT angiography, Turk GogusKalpDamar Cer Derg. 2010;18(4)290-292.

Abbreviations

$\begin{array}{lll}\text { AV } & - & \text { Atrioventricular } \\ \text { SA } & - & \text { Sinuatrial } \\ \text { RCA } & - & \text { Right Coronary Artery } \\ \text { LCA } & - & \text { Left Coronary Artery } \\ \text { Lt } & - & \text { Left } \\ \text { Rt } & - & \text { Right }\end{array}$

\section{How to cite this article?}

Verma R, Guha BK, Shrivastava SK. Anatomical Study of the Variations of Sinuatrial and Atrioventricular Nodal Arteries in Human Heart. Int J Med Res Rev 2014;2(3):209-214. doi:10.17511/ijmrr.2014.i03.10 